\title{
On the Economics of Efficiency, Bargaining and Welfare Distribution
}

\author{
Jean-Paul Chavas', Mingcong Pan ${ }^{1,2}$ \\ ${ }^{1}$ Department of Agricultural and Applied Economics, Taylor Hall, University of Wisconsin, Madison, USA \\ ${ }^{2}$ Department of Political Science, North Hall, University of Wisconsin, Madison, USA \\ Email: jchavas@wisc.edu, mingcong.pan@wisc.edu
}

How to cite this paper: Chavas, J.-P., \& Pan, M. C. (2022). On the Economics of Efficiency, Bargaining and Welfare Distribution. Theoretical Economics Letters, 12, 123-148.

https://doi.org/10.4236/tel.2022.121008

Received: December 8, 2021

Accepted: February 5, 2022

Published: February 8, 2022

Copyright () 2022 by author(s) and Scientific Research Publishing Inc. This work is licensed under the Creative Commons Attribution International License (CC BY 4.0).

http://creativecommons.org/licenses/by/4.0/

(c) (i) Open Access

\begin{abstract}
This paper develops a joint analysis of efficiency and distributional issues in an economy in general equilibrium with a focus on bargaining under bounded rationality. Our analysis relies on evolutionary strategies based on the NashHarsanyi bargaining model, but we go beyond the Nash-Harsanyi model by generalizing it with ordinal preferences as well as allowing for inefficient bargaining agreements. We show that our evolutionary schemes converge to bargaining agreements under general conditions. The analysis covers the case where the bargaining agreement is inefficient as well as the case where the bargaining process converges to an efficient allocation located on the Pareto utility frontier. We show that the outcome of the bargaining process can be represented by the simple maximization of a "generalized Nash product". We explore the implications of bargaining agreements for income distribution. Finally, we discuss our model's insights in analyzing the performance of an economy, emphasizing the roles of preferences, decentralization, and public goods.
\end{abstract}

\section{Keywords}

Efficiency, Bargaining, Distribution, Bounded Rationality, Ordinal

Preferences, Public Goods

\section{Introduction}

The concept of efficiency is a cornerstone of economic analysis, and the linkages between competitive markets and Pareto efficiency have indicated how decentralized decisions can generate efficient allocations in a market economy (e.g., Debreu, 1959). But three sets of issues remain. First, Pareto efficiency does not provide guidance on evaluating income and welfare distribution: some alloca- 
tions can be found efficient even under extreme forms of income inequality (Crockett et al., 2011). Yet, income and welfare inequality have always been part of the design, implementation, and evaluation of economic policy (e.g., Milanovic, 2013; Piketty, 2014), indicating the need to incorporate distributional issues in the analysis of efficiency and market outcomes. Second, while markets play an important role in a global economy, the management of externalities and public goods is often difficult and typically relies on contracts and/or government policy (e.g., Coase, 1960). This suggests that the role of public goods is important in the evaluation of efficiency and welfare analysis. Third, obtaining and processing information about resource scarcity can be challenging, and individuals often exhibit "bounded rationality" as they have limited cognitive abilities that affect their decisions (Simon, 1955). There is strong evidence that cognitive limitations can make it difficult for individuals to make decisions in complex situations (e.g., Oprea, 2020), suggesting that the evaluation of resource allocation and welfare distribution should consider allowing for possible inefficiency. The objective of this paper is to address these three sets of issues and to propose a formal and unified framework supporting a refined analysis of economic behavior and policy.

This paper develops a joint analysis of efficiency and distribution issues, with a focus on the role of bargaining under bounded rationality. It builds on the seminal work of Nash $(1950,1953)$ and Harsanyi $(1950,1963,1977)$ on bargaining $^{1}$. The Nash-Harsanyi bargaining model provides guidance on welfare distribution: relying on threat points that reflect the bargaining position of each individual, it identifies a unique point on the Pareto utility frontier that would be acceptable to all parties. But as noted in Nash $(1950,1953)$ and Harsanyi $(1950$, 1963, 1977), the Nash-Harsanyi bargaining model has two limitations: 1) it is based on the expected utility model and its cardinal representation of preferences; and 2) it focuses on choosing an efficient allocation on the Pareto utility frontier. Our paper goes beyond the Nash-Harsanyi model in two ways: 1) we propose to model bargaining based on ordinal preferences; and 2) we consider bargaining agreements that are not necessarily efficient. Our analysis builds on evolutionary schemes where decisions are made reflecting limited information under bounded rationality (e.g., Sandholm, 2010). Besides being more realistic, evolutionary games keep the option open that they may converge to efficient allocations (Vega-Redondo, 1997; Ostrom, 2000; Gintis, 2007; Mandel \& Gintis, 2016; Chavas \& Wang, 2021). We propose evolutionary schemes representing bargaining, where each step of the bargaining process identifies who is willing to

${ }^{1}$ The Nash-Harsanyi approach focuses on cooperative bargaining. This differs from the non-cooperative approach to bargaining (Rubinstein, 1982, 1998; Chatterjee et al., 1993). While the two approaches are not mutually exclusive (Binmore et al., 1986), we note that bounded rationality means that individuals can have difficulties evaluating efficiency as well as strategic behavior (including coalition formation). Also, the non-existence of core allocations (defined as being coalition-proof) can be problematic (Forges et al., 2002; Compte \& Jehiel, 2010). We see these issues as significant limitations of the non-cooperative bargaining approach. Our focus on cooperative bargaining avoids these issues. 
make a concession depending on the relative perceived cost of bargaining failure. We show how such evolutionary schemes converge to bargaining agreements under general conditions. Under bounded rationality, the bargaining agreements may be inefficient. We then identify the magnitude of the associated efficiency loss. In this context, we explore the implications of a bargaining agreement for income distribution. Depending on the purchasing power of each individual at the threat points, we show how income distribution can vary from egalitarian to very unequal. We also consider the case where the bargaining process would converge to an efficient allocation located on the Pareto utility frontier. We show that the outcome of the bargaining process (whether it is efficient or not) can be represented by the simple maximization of a "generalized Nash product". This is an important generalization of the Nash-Harsanyi bargaining model as it applies under general ordinal preferences and allows for possible inefficiency (under bounded rationality). Finally, we discuss the implications of our analysis for the performance of the economy, emphasizing the roles of preferences, decentralization, and public goods. While our model is consistent with the efficiency of markets, it provides new insights into three sets of issues: 1) the role of bounded rationality in economic analysis; 2 ) the role of public goods and their management in public policy; and 3) an integrated evaluation of the importance of income and welfare distribution in society.

The paper is organized as follows. Section 2 presents an overview of the economic efficiency of an economy in general equilibrium. Section 3 develops a model of bargaining under ordinal preferences, with a focus on evolutionary strategies. Section 4 evaluates the linkages between bargaining and efficiency. Sections 5 and 6 discuss the role of threat points and their effects on income distribution. Finally, Section 7 discusses the economic and policy implications of our analysis.

\section{Efficiency}

This section sets up the notation for resource allocation in an economy and presents a general equilibrium characterization of Pareto efficiency that will be an important building block in our analysis. Consider a society composed of $n$ members, with $n \geq 2$ and $N=\{1, \cdots, n\}$. Decisions are made about both consumption decisions and production activities. For the $i$-th individual, consumption decisions include $m$ private goods $x_{i} \in X_{i} \subset \mathbb{R}^{m}$ and leisure time $z_{i} \in[0, T]$, $i \in N, T$ denoting the total time available to any individual. Consumption decisions also include public goods $x_{0} \in X_{0}$. Let

$x \equiv\left(x_{0}, x_{N}\right) \in X \equiv X_{0} \times X_{1} \times \cdots \times X_{n}$ and $z=\left(z_{1}, \cdots, z_{n}\right) \in[0, T]^{n}$. We assume that the sets $X_{0}$ and $X$ are closed and convex. The goods $\left(x_{0}, x_{N}\right)$ are also produced. Denote the aggregate production of private goods by $y \in \mathbb{R}^{m}$. Feasibility requires that consumer goods are also produced, implying that $\sum_{i \in N} x_{i} \leq y$. Throughout, we use the netput notation where positive quantities $\left(y_{j} \geq 0\right)$ corresponds to outputs while negative quantities $\left(y_{j} \leq 0\right)$ corresponds to inputs. 
The aggregate production technology is represented by the feasible set $F$ where $\left(x_{0}, y, T-z_{1}, \cdots, T-z_{n}\right) \in F \subset X_{0} \times \mathbb{R}^{m} \times[0, T]^{n}$ means that $\left(x_{0}, y, T-z_{1}, \cdots, T-z_{n}\right)$ is feasible, where $\left(T-z_{i}\right)$ is the amount of time spent by the $i$-th individual on production activities, $i \in N$. In this case, production feasibility simply states that goods $\left(x_{0}, y\right)$ can be produced using labor input $\left(T-z_{1}, \cdots, T-z_{n}\right)$. Throughout the paper, we assume that the set $F$ is non-empty and closed.

We study the economics of choosing an allocation $(x, y, z)$. The preferences of the $i$-th individual are represented by the utility function $u_{i}\left(x_{0}, x_{i}, z_{i}\right), i \in N$. We make the following assumptions:

Assumption As1: The utility function $u_{i}\left(x_{0}, x_{i}, z_{i}\right)$ is continuous in $\left(x_{0}, x_{i}, z_{i}\right) \in X_{0} \times X_{i} \times[0, T]$; and for any $\left(x_{0}, z_{i}\right) \in X_{0} \times[0, T], u_{i}\left(x_{0}, x_{i}, z_{i}\right)$ is quasi-concave in $x_{i} \in X_{i}, i \in N$.

Assumption As2: Let $g \geq 0$ be a non-zero bundle of private goods. For each $i \in N$ and any $\left(x_{0}, x_{i}, z_{i}\right) \in X_{0} \times X_{i} \times[0, T]$, the utility function $u_{i}\left(x_{0}, x_{i}+\alpha g, z_{i}\right)$ is strictly increasing in $\alpha \in \mathbb{R}$.

Assumption As3: Conditional on $\left(x_{0}, T-z\right)$, the set $Y\left(x_{0}, z\right)=\left\{y:\left(x_{0}, y, T-z\right) \in F\right\}$ is convex.

The strict monotonicity assumption in As2 is a form of non-satiation: $u_{i}\left(x_{0}, x_{i}+\alpha g, z_{i}\right)$ being strictly increasing in $\alpha$ implies that individual preferences are non-satiated in private goods. Note the generality of the approach. First, it allows for public goods (which includes public "bads" as well as externalities). Second, As3 does not assume that the set $F$ is necessarily convex. For example, it allows for a technology exhibiting increasing returns to scale in the production of the public goods $x_{0}$. Third, the approach treats labor as a differentiated product allowing for labor productivity to vary across individuals. Fourth, the allocation $(x, y, z)$ can occur over time, allowing for an intertemporal analysis: in this case, the vector $y$ would include saving/investment (or borrowing if negative) that allows for resource transfers across periods, the consumer goods $x$ would represent consumption path over time and the utility functions would reflect time preferences. Fifth, the analysis can apply under uncertainty. Representing the uncertainty by states of nature, the elements of the vector $(x, y, z)$ would then be defined as being state-dependent, with the utility functions representing risk preferences (Debreu, 1959) ${ }^{2}$. Note that this also allows for heterogeneous information ${ }^{3}$ across individuals (Radner, 1968).

Our analysis will rely in part on the classical concept of Pareto efficiency. We define a feasible allocation to be Pareto efficient if there does not exist another feasible allocation that can make one individual better off without making anyone else worse off.

Again, let $g \geq 0$ be a non-zero bundle of private goods. Consider the follow-

${ }^{2}$ Under uncertainty, the reference bundle $g$ in assumption As2 would be taken to be state-independent so that any individual receiving $(\alpha g)$ can be interpreted as an $e x$ ante welfare measure. See below.

${ }^{3}$ Heterogeneous information would be represented by different partitions of the state space across individuals. 
ing maximization problem

$$
\begin{gathered}
W(U)=\max _{x, y, z, \beta}\left\{\sum_{i \in N} \beta_{i}: u_{i}\left(x_{0}, x_{i}-\beta_{i} g, z_{i}\right) \geq U_{i}, i \in N ;\right. \\
\left.\sum_{i \in N} x_{i} \leq y,\left(x_{0}, y, T-z\right) \in F, x \in X, \beta \in \mathbb{R}^{n}\right\},
\end{gathered}
$$

where $U_{i}$ is a reference utility level for the $i$-th individual, $i \in N$, and $U=\left(U_{1}, \cdots, U_{n}\right)$. Conditional on $U=\left(U_{1}, \cdots, U_{n}\right)$, denote the solution to (1) by $x^{*}(U), y^{*}(U), z^{*}(U)$ and $\beta^{*}(U)$. The objective function in (1) measures the number of units of the reference bundle $g$ the $n$ individuals are willing to give up starting with allocation $(x, y, z)$ to obtain utility levels $U$. Below, we consider the case where the bundle $g$ is defined to be worth $\$ 1$. In this context, $\sum_{i \in N} \beta_{i}$ has a simple welfare interpretation: it is a monetary measure of aggregate willingness-to-pay. It follows that $W(U)$ in (1) is the maximum aggregate willingness-to-pay of the $n$ individuals, conditional on $U$. We make the additional assumption:

Assumption As4: Let $U \in \mathcal{U}$, where $\mathcal{U}=\left\{U^{\prime}: W\left(U^{\prime}\right) \geq 0,\left\{x_{i}^{*}\left(U^{\prime}\right)-\alpha_{i} g: \alpha_{i}>0\right\} \cap X_{i} \neq \varnothing, i \in N\right\}$.

Assumption As4 imposes two conditions: 1) fiscal feasibility represented by a non-negative aggregate willingness-to-pay: $W(U) \geq 0$; and 2) the condition $\left\{x_{i}^{*}(U)-\alpha_{i} g: \alpha_{i}>0\right\} \cap X_{i} \neq \varnothing, i \in N$, which rules out situations of complete destitution. This last condition guarantees that each individual is able to give up some private goods in $g$ so that individual willingness-to-pay remains a valid welfare measure. Note that $U \in \mathcal{U}$ in As4 still allows for a wide distribution of purchasing power across individuals (including situations of poverty where some individuals have limited purchasing power and low consumption of private goods).

While Equation (1) is conditional on $U$, under assumption As4, we consider the following choice for $U$ :

$$
U^{*} \in\{U: W(U)=0, U \in \mathcal{U}\} .
$$

As stated next, Equations (1) and (2) provide a basis to evaluate efficiency. (The proofs of our propositions, corollaries, and lemmas are presented in the Appendix).

Proposition 1. Under assumptions As1 - As4, an allocation $\left(x^{*}, y^{*}, z^{*}\right)$ is $\mathrm{Pa}$ reto efficient if and only if it satisfies Equations (1) and (2).

For a given welfare distribution $U=\left(U_{1}, \cdots, U_{n}\right)$, Equation (1) associates an efficient allocation with the maximization of aggregate willingness-to-pay. And Equation (2) states that the distribution of welfare $U=\left(U_{1}, \cdots, U_{n}\right)$ is such that the maximized aggregate value $W(U)$ is entirely redistributed among the $n$ individuals. It has a useful interpretation: choosing $U=\left(U_{1}, \cdots, U_{n}\right)$ such that $W(U)=0$ defines the utility frontier. For example, when $n=2$, solving $W\left(U_{1}, U_{2}\right)=0$ for $U_{2}$ gives the utility frontier $U_{2}\left(U_{1}\right)$, which traces out the utilities $\left\{U_{1}, U_{2}\left(U_{1}\right)\right\}$ that can be attained under an efficient allocation. Thus, when $n \geq 2$, Equations (1) and (2) identify the set of efficient allocations along 
the utility frontier. It makes it clear that efficient allocations are not unique, as they change depending on the values taken by $U_{1}$ and $U_{2}\left(U_{1}\right)$. Which point on the utility frontier is actually obtained depends on the distribution of welfare within society. In turn, since $x^{*}, y^{*}$ and $z^{*}$ depend on $U^{*}$, the welfare levels obtained by each individual will affect behavior. In that sense, both efficiency and distribution issues are relevant in the analysis of private decisions and public choice.

To establish linkages between Proposition 1 and previous literature, consider the case of a market economy where $p \in \mathbb{R}_{+}^{m}$ denotes the prices of private consumer goods. As noted above, we normalize prices such that $p g=1$, meaning that $W(U)$ in (1) is a welfare measure with a monetary interpretation. In this context, an alternative representation of efficiency is presented next.

Corollary 1. Under assumptions As1-As4, an allocation $\left(x^{*}, y^{*}, z^{*}\right)$ is Pareto efficient if and only if it satisfies

$$
\begin{gathered}
b_{i}\left(x_{0}, x_{i}, z_{i}, U_{i}\right)=\max _{\beta_{i}}\left\{\beta_{i}: u_{i}\left(x_{0}, x_{i}-\beta_{i} g, z_{i}\right) \geq U_{i}\right\}, i \in N \\
e_{i}\left(p, x_{0}, z_{i}, U_{i}\right)=\min _{x_{i}}\left\{p x_{i}-b_{i}\left(x_{0}, x_{i}, z_{i}, U_{i}\right): x_{i} \in X_{i}\right\} \\
=\min _{x_{i}}\left\{p x_{i}: u_{i}\left(x_{0}, x_{i}, z_{i}\right) \geq U_{i}, x_{i} \in X_{i}\right\}, i \in N \\
\pi\left(p, x_{0}, z\right)=\max _{y}\left\{p y:\left(x_{0}, y, T-z\right) \in F\right\} \\
W(U)=\min _{p \geq 0} \max _{x_{0}, z}\left\{\pi\left(p, x_{0}, z\right)-\sum_{i \in N} e_{i}\left(p, x_{0}, z_{i}, U_{i}\right): x_{0} \in X_{0}, z \in[0, T]^{n}\right\}
\end{gathered}
$$

and

$$
U^{*} \in\{U: W(U)=0, U \in \mathcal{U}\} .
$$

Equation (3) gives the benefit function $b_{i}\left(x_{0}, x_{i}, z_{i}, U_{i}\right)$ proposed and discussed in Luenberger (1992). Equation (5) defines an expenditure minimization problem conditional on $\left(x_{0}, z_{i}\right)$, where $e_{i}\left(p, x_{0}, z_{i}, U_{i}\right)$ is a standard expenditure function measuring the purchasing power of the $i$-th individual, $i \in N$. As showed in Luenberger (1992), the private expenditure function $e_{i}\left(p, x_{0}, z_{i}, U_{i}\right)$ is dual to the benefit function. Denoting by $w_{i}$ the income received by the $i$-th individual, the expenditure minimization problem used to generate the expenditure function is also dual to the utility maximization problem $V_{i}\left(p, x_{0}, z_{i}, w_{i}\right)=\max _{x_{i}}\left\{u_{i}\left(x_{0}, x_{i}, z_{i}\right): p x_{i} \leq w_{i}, x_{i} \in X_{i}\right\}$ where $V_{i}\left(p, x_{0}, z_{i}, w_{i}\right)$ is the indirect utility function satisfying $w_{i}=e_{i}\left(p, x_{0}, z_{i}, V_{i}\left(p, x_{0}, z_{i}, w_{i}\right)\right), i \in N$ (Deaton \& Muellbauer, 1980). Under differentiability, $\partial e_{i} / \partial\left(x_{0}, z_{i}\right)$ measures the shadow prices of $\left(x_{0}, z_{i}\right)$ for each $i \in N$. Equation (6) is an income maximization problem, yielding the aggregate income function $\pi\left(p, x_{0}, z\right)$. Under differentiability, $\partial \pi / \partial\left(x_{0}, z\right)$ measures the shadow cost of $\left(x_{0}, z\right)$. Finally, Equation (7) states that the efficient choice of $\left(x_{0}, z\right)$ is consistent with the maximization of net aggregate income $\left[\pi\left(p, x_{0}, z\right)-\sum_{i \in N} e_{i}\left(p, x_{0}, z_{i}, U_{i}\right)\right]$. When $\left(x_{0}, z\right)$ include externalities, this identifies the efficient management of exter- 
nalities (Coase, 1960; Chavas, 2015). Also, Equation (7) identifies the marketclearing prices $p^{*}$ for private goods supporting an efficient allocation in general equilibrium.

From Equation (7) and assumption As4, feasibility means that the aggregate budget constraint can be written as $\sum_{i \in N} e_{i}\left(p, x_{0}, z_{i}, U_{i}\right) \leq \pi\left(p, x_{0}, z\right)$ or $W(U) \geq 0$. From Equation (2) or (8), Pareto efficiency means that $\sum_{i \in N} e_{i}\left(p, x_{0}, z_{i}, U_{i}\right)=\pi\left(p, x_{0}, z\right)$, implying that the aggregate budget constraint is necessarily binding. If $W(U) \geq 0$ under feasibility and $W(U)=0$ under Pareto efficiency, it follows that $W(U)>0$ is necessarily associated with inefficiency. As discussed in the introduction, under bounded rationality, individuals can have cognitive difficulties in making decisions in complex situations (Simon, 1955; Oprea, 2020), indicating the need to explore inefficient allocations. The inefficiency can come from three sources: 1) society does not maximize income which lowers the purchasing power of consumers; 2) the $n$ consumers do not minimize their expenditures; 3 ) some of the income is not spent, with adverse effects on welfare. Our analysis will allow for economic inefficiency as discussed below.

The aggregate income function $\pi\left(p, x_{0}, z\right)$ is given in (6). Let $y^{c}\left(p, x_{0}, z\right)$ be the solution of the maximization problem in (6). Under differentiability, note that Hotelling's lemma gives $y^{c}\left(p, x_{0}, z\right)=\partial \pi\left(p, x_{0}, z\right) / \partial p$. Comparing $y^{c}\left(p, x_{0}, z\right)$ with the observed decisions $y$, Equation (6) can be used to investigate possible departure from efficiency, with $\left[p y^{c}\left(p, x_{0}, z\right)-p y\right] \geq 0$ providing a measure of production inefficiency. These departures can come from technical inefficiency (if production of private goods is not situated on the boundary of the feasible set $F$ ), and/or allocative inefficiency (if production decisions do not maximize aggregate income as given in Equation (6)). In addition, the efficient choices of public goods $x_{0}$ and leisure $z$ correspond to the maximization of net aggregate income $\left[\pi\left(p, x_{0}, z\right)-\sum_{i \in N} e_{i}\left(p, x_{0}, z_{i}, U_{i}\right)\right]$ as given in Equation (7). Finally, from (8), $W(U)=0$ is the aggregate budget constraint stating that aggregate income $\pi\left(p, x_{0}, z\right)$ is entirely redistributed among the $n$ individuals in society. Clearly, how aggregate income is distributed affects the purchasing power of each individual and thus the distribution of welfare in society. In the following sections, we will firstly introduce bargaining among members of society, and then connect it to distributional and efficiency issues for a joint analysis of efficiency and welfare distribution.

\section{Bargaining}

How to choose a point $U^{*}$ on the Pareto utility frontier defined by Equation (2) or (8)? Many efficient points exist along the Pareto utility frontier. Moving along the Pareto utility frontier is associated with changing individual utilities $\left(U_{1}, \cdots, U_{n}\right)$ and the associated income distribution. In an egalitarian society, all individuals would have the same purchasing power. But efficiency can also be associated with unequal distribution of income if a few individuals receive a 
large part of the aggregate income $\pi\left(p, x_{0}, z\right)$ (Crockett et al., 2011). This indicates a need to go beyond Pareto efficiency and to examine income and welfare distribution within society.

This section investigates welfare distribution as the outcome of a bargaining process among the $n$ members of society. The analysis is inspired by seminal work on bargaining by Nash $(1950,1953)$ and Harsanyi $(1950,1963,1977)$. As noted in previous literature, the Nash-Harsanyi approach is limiting as it was presented under the expected utility model where utilities are defined up to a positive linear transformation. We extend the Nash-Harsanyi approach by presenting our analysis under ordinal preferences.

The analysis starts with threat points. Threat points are defined as feasible allocations representing outcomes that would arise in the case of bargaining failure among the $n$ individuals. We denote the threat allocation for the $i$-th individual by $\left(x_{0 i}^{t}, x_{i}^{t}, y_{i}^{t}, z_{i}^{t}\right), i \in N$. The utilities associated with the threat points are $U_{i}^{t}=u_{i}\left(x_{0 i}^{t}, x_{i}^{t}, z_{i}^{t}\right), i \in N$ where $U^{t}=\left(U_{1}^{t}, \cdots, U_{n}^{t}\right) \in \mathcal{U}$. In this section, we treat the threat allocations as given. The determination of threat strategies and the factors affecting bargaining failure are discussed in Section 5 .

Using Equation (3), the benefit function $b_{i}\left(x_{0}, x_{i}, z_{i}, U_{i}^{t}\right)$ is the willingnessto-pay of the $i$-th individual starting with $\left(x_{0}, x_{i}, z_{i}\right)$ to avoid facing the threat utility $U_{i}^{t}$. Thus, for a given $\left(x_{0}, x_{i}, z_{i}\right), b_{i}\left(x_{0}, x_{i}, z_{i}, U_{i}^{t}\right)$ is a measure of the welfare loss perceived by the $i$-th individual facing the prospect of receiving the threat allocation: the greater $b_{i}\left(x_{0}, x_{i}, z_{i}, U_{i}^{t}\right)$, the greater the associated welfare loss.

To the extent that the threat outcomes are feasible and always available, no individual is willing to accept any payoff less favorable than his/her threat point. Thus, we restrict our bargaining analysis to the allocations $(x, y, z)$ satisfying $u_{i}\left(x_{0}, x_{i}, z_{i}\right) \geq U_{i}^{t}, i \in N$. It follows from (3) that $b_{i}\left(x_{0}, x_{i}, z_{i}, U_{i}^{t}\right) \geq 0, i \in N$, stating that the willingness-to-pay to avoid the threat points is non-negative. It this context, $W\left(U^{t}\right) \geq 0$ provide a measure of the aggregate welfare loss associated with bargaining failure. We propose to use $b_{i}\left(x_{i}, x_{0}, z_{i}, U_{i}^{t}\right)$ to evaluate the bargaining position of the $i$-th individual, $i \in N$.

Definition 1: The $i$-th individual facing $\left(x_{0}, x_{i}, z_{i}\right)$ is less willing to accept a bargaining failure than individual $i$ 'if

$$
b_{i}\left(x_{0}, x_{i}, z_{i}, U_{i}^{t}\right)>b_{i^{\prime}}\left(x_{0}, x_{i^{\prime}}, z_{i^{\prime}}, U_{i^{\prime}}^{t}\right), i \in N, i^{\prime} \in N-i .
$$

Definition 1 states that a move from an allocation $(x, y, z)$ to the threat points would decrease the purchasing power more for individual $i$ than individual $i$. It asserts that the $i$-th individual, compared with $i^{\prime}$-th one, is less willing to face a bargaining failure when a bargaining failure would reduce his/her welfare more than individual $i$. Thus, the greater $b_{i}\left(x_{0}, x_{i}, z_{i}, U_{i}^{t}\right)$ is, the less the individual is willing to accept a bargaining failure. And we propose the following definition of a bargaining agreement.

Definition 2: A feasible allocation $(x, y, z)$ is a bargaining agreement for all $n$ 
individuals if

$$
b_{i}\left(x_{0}, x_{i}, z_{i}, U_{i}^{t}\right)=M\left(x, z, U^{t}\right) \text { for all } i \in N \text {, }
$$

where

$$
M\left(x, z, U^{t}\right)=\max _{i}\left\{b_{i}\left(x_{0}, x_{i}, z_{i}, U_{i}^{t}\right): i \in N\right\} .
$$

Definition 2 states that a feasible allocation $(x, y, z)$ is a bargaining agreement when all $n$ individuals are equally willing to accept a bargaining failure. Building on evolutionary games where decisions are made reflecting limited information under bounded rationality (e.g., Sandholm, 2010; Vega-Redondo, 1997; Gintis, 2007; Chavas \& Wang, 2021), we propose an iterative scheme representing the bargaining process. We show how the scheme can converge to a bargaining agreement and discuss the efficiency properties of agreements.

Bargaining scheme S:

- Step S1: Start at iteration $k=1$. Propose a feasible allocation $\left(x^{k}, y^{k}, z^{k}\right)$. Let $\Delta_{i}^{k}=b_{i}\left(x_{0}^{k}, x_{i}^{k}, z_{i}^{k}, U_{i}^{t}\right), i \in N$, and $M^{k}=\max _{i}\left\{\Delta_{i}^{k}: i \in N\right\}$.

- Step S2: Find the set $N^{k}$ of individuals being least willing to face a bargaining failure

$$
N^{k}=\left\{i: \Delta_{i}^{k}=M^{k}, i \in N\right\}
$$

- Step S3:

○ Step S3a: If $N^{k}=N$, then stop the bargaining process at $k^{\#}=k$ and announce $\left(x^{k^{\#}}, y^{k^{\#}}, z^{k^{\#}}\right)$ as a bargaining agreement.

○ Step S3b: If $N^{k} \neq N$, propose a feasible allocation $\left(x^{k+1}, y^{k+1}, z^{k+1}\right)$ satisfying

$$
\Delta_{i}^{k+1}<\Delta_{i}^{k}, i \in N^{k},
$$

and

$$
\Delta_{i}^{k+1}<M^{k}, i \in N-N^{k},
$$

where $\Delta_{i}^{k+1}=b_{i}\left(x_{0}^{k+1}, x_{i}^{k+1}, z_{i}^{k+1}, U_{i}^{t}\right), i \in N$, and $M^{k+1}=\max _{i}\left\{\Delta_{i}^{k+1}: i \in N\right\}$.

Then, let $k=k+1$ and go to step S2.

The bargaining scheme $S$ involves identifying the individuals who are the least willing to face a bargaining failure. At the $k$-th iteration, the set of these individuals is denoted by $N^{k}$ in Equation (12) in step S2. In a way consistent with Definition 2, step S3a identifies a bargaining agreement occurring when $N^{k}=N$, i.e. when all $n$ individuals are equally willing to face a bargaining failure. In step S3b, Equation (13) states that the individuals in $N^{k}$ are the ones making a concession at the $k$-th iteration, where making a concession means reducing current gains relative to threat points and therefore increasing their willingness to face a bargaining failure. Note that, as in Zeuthen (1930), the individuals making concessions are the ones least willing to face a bargaining failure (Zeuthen, 1930; Harsanyi, 1950, 1977). As the bargaining process given in S moves in the direction of equalizing the willingness to accept a bargaining failure, upon 
convergence, the process of making concessions in S leads to a bargaining agreement.

Proposition 2: Upon convergence, the bargaining scheme S identifies a bargaining agreement $\left(x^{k^{\#}}, y^{k^{\#}}, z^{k^{\#}}\right)$.

Proposition 2 identifies a bargaining agreement. From Definition 2, a bargaining agreement occurs when all individuals are equally willing to face a bargaining failure. Note that Proposition 2 does not say that convergence will always occur; and it does not say that a bargaining agreement is unique. These two issues will be revisited and explored in more detail in the next section. For example, Proposition 4 presents a case where convergence to a bargaining agreement is guaranteed.

\section{Bargaining and Efficiency}

Note that Proposition 2 does not require the bargaining agreement $\left(x^{k^{\#}}, y^{k^{\#}}, z^{k^{\#}}\right)$ to be Pareto efficient. Thus, under bounded rationality, it allows for inefficient bargaining outcomes. If the bargaining outcome $\left(x^{k^{\#}}, y^{k^{\#}}, z^{k^{\#}}\right)$ is not Pareto efficient, there are untapped efficiency gains. Letting $U_{i}^{k^{\#}}=u_{i}\left(x_{0}^{k^{\#}}, x_{i}^{k^{\#}}, z_{i}^{k^{\#}}\right), i \in N$ and $U^{\#}=\left(U_{1}^{k^{\#}}, \cdots, U_{n}^{k^{\#}}\right)$, the corresponding aggregate efficiency gain would be $W\left(U^{\#}\right)>0$.

Could the bargaining scheme $\mathrm{S}$ be modified to converge to an efficient allocation?

Bargaining scheme $S^{\prime}$ : The scheme $S^{\prime}$ is the same as S except that step S3 is replaced by S3':

- Step S3': Let $U_{i}^{k}=u_{i}\left(x_{0}^{k}, x_{i}^{k}, z_{i}^{k}\right)$ and $U^{k}=\left(U_{1}^{k}, \cdots, U_{n}^{k}\right)$.

○ Step S3a': If $N^{k}=N$ and $W\left(U^{k}\right)=0$, then stop the bargaining process at $k^{*}=k$ and announce $\left(x^{k^{*}}, y^{k^{*}}, z^{k^{*}}\right)$ as a bargaining agreement.

○ Step S3b': If $N^{k} \neq N$ or $W\left(U^{k}\right)>0$, propose a feasible allocation $\left(x^{k+1}, y^{k+1}, z^{k+1}\right)$ satisfying Equations (13a) and (13b) if $N^{k} \neq N$, and

$$
W\left(U^{k+1}\right)<W\left(U^{k}\right) \text { if } W\left(U^{k}\right)>0
$$

where $U_{i}^{k+1}=u_{i}\left(x_{0}^{k+1}, x_{i}^{k+1}, z_{i}^{k+1}\right), U^{k+1}=\left(U_{1}^{k+1}, \cdots, U_{n}^{k+1}\right)$, $\Delta_{i}^{k+1}=b_{i}\left(x_{0}^{k+1}, x_{i}^{k+1}, z_{i}^{k+1}, U_{i}^{t}\right), i \in N$, and $M^{k+1}=\max _{i}\left\{\Delta_{i}^{k+1}: i \in N\right\}$. Then, let $k=k+1$ and go to step S2.

Scheme $S^{\prime}$ differs from $S$ in two ways. First, $W\left(U^{k}\right)=0$ has been added in step S3a'. From Proposition 1, this corresponds to Pareto efficiency. Second, when $W\left(U^{k}\right)>0$, Equation (14) has been added to the iterative scheme. Equation (14) states that the bargaining process must reduce the distance to the $\mathrm{Pa}$ reto utility frontier across iterations from $k$ to $k+1$. This implies that the iterative process necessarily moves toward the Pareto utility frontier. Upon convergence, from S3a', this leads to an allocation on the Pareto utility frontier.

Building on Proposition 2, we have the following result. 
Proposition 3: Upon convergence, the bargaining scheme $S$ ' identifies an efficient bargaining agreement $\left(x^{k^{*}}, y^{k^{*}}, z^{k^{*}}\right)$ that corresponds to a unique point on the Pareto utility frontier.

Proposition 3 states that the bargaining process given in $S^{\prime}$ converges to a unique point on the Pareto utility frontier. The bargaining schemes $S$ and $S$ ' have some nice properties. First, they involve simple iterations that may reflect the steps taken during an actual bargaining session. Second, upon convergence, scheme S' finds a bargaining agreement for an allocation that is Pareto efficient and where all individuals are equally willing to face a bargaining failure. Third, this bargaining process $S$ ' identifies a unique point on the Pareto utility frontier. This unique point is linked directly with the threat of bargaining failure, thus stressing the importance of threat points.

Note that the identification of a unique point on the Pareto utility frontier was obtained from a bargaining process. It did not require the specification of a social welfare function. Yet, a social welfare function can always be found to rationalize observed behavior. For example, if the Pareto utility frontier is concave, then there exists a hyperplane tangent to the utility frontier at some evaluation point. In this case, the slopes of this hyperplane can be treated as Bergsonian weights in a social welfare function. But changing these Bergsonian weights can rationalize any point of the utility frontier, meaning that a social welfare function does not really help to identify the factors affecting distribution issues. In contrast, our bargaining approach and its reliance on threat points do provide the additional information we can use in the investigation of income distribution within society.

Below, we provide a simple representation of the outcome of the bargaining process $S$ '.

Proposition 4. Consider the following optimization problem

$$
\begin{aligned}
& \max _{x, y, z, U}\left\{\prod_{i \in N}\left[b_{i}\left(x_{0}, x_{i}, z_{i}, U_{i}^{t}\right)-b_{i}\left(x_{0}, x_{i}, z_{i}, U_{i}\right)\right]: \sum_{i \in N} b_{i}\left(x_{0}, x_{i}, z_{i}, U_{i}\right) \geq 0 ;\right. \\
& \left.\sum_{i \in N} x_{i} \leq y ; b_{i}\left(x_{0}, x_{i}, z_{i}, U_{i}^{t}\right) \geq 0, i \in N ; x_{N} \in X^{n} ;\left(x_{0}, y, T-z\right) \in F, U \in \mathcal{U}\right\}
\end{aligned}
$$

which has a solution $\left(x^{e}, y^{e}, z^{e}, U^{e}\right)$. The allocation $\left(x^{e}, y^{e}, z^{e}\right)$ is an efficient bargaining agreement.

Proposition 4 is an extension of Nash bargaining under ordinal preferences (Nash, 1950). As such, the term $\prod_{i \in N}\left[b_{i}\left(x_{0}, x_{i}, z_{i}, U_{i}^{t}\right)-b_{i}\left(x_{0}, x_{i}, z_{i}, U_{i}\right)\right]$ in (15) is a generalized "Nash product". The maximization problem in (15) subject to several constraints: the feasibility constraints $\sum_{i \in N} b_{i}\left(x_{0}, x_{i}, z_{i}, U_{i}\right) \geq 0$ and $\sum_{i \in N} x_{i} \leq y$; and the incentive compatibility constraints $b_{i}\left(x_{0}, x_{i}, z_{i}, U_{i}^{t}\right) \geq 0$,

${ }^{4}$ The Nash bargaining model was first proposed by Nash $(1950,1953)$ under the expected utility model. Extensions of the Nash bargaining model under ordinal preferences have been explored by Rubinstein et al. (1992) and Hanany and Safra (2000). Our approach also applies under ordinal preferences. But it goes beyond Rubinstein et al. (1992) or Hanany and Safra (2000) in the sense that our approach does not rely on probability assessments. 
$i \in N$. When combined with Proposition 3, Proposition 4 states that the constrained maximization of the generalized Nash product in (15) picks a unique point on the Pareto utility frontier that is also a bargaining agreement as identified in scheme S'. This is one of our important results: combining bargaining and efficiency settles the issue of how welfare is distributed within society.

While Proposition 4 identifies scenarios where bargaining leads to efficient allocations under bargaining scheme $S$ ', we also consider allocations associated with bargaining agreements that may be inefficient. In general, the bargaining scheme S can generate inefficient bargaining outcomes. And inefficiency can arise if the bargaining individuals fail to identify the benefits from efficiency gains (e.g., due to cognitive limitations and/or information cost; see Simon (1955), Oprea (2020)).

To examine the cost of inefficient agreements, consider a bargaining agreement $\left(x^{a}, y^{a}, z^{a}\right)$ associated with scheme $\mathrm{S}$. How does it compare with a bargaining agreement $\left(x^{e}, y^{e}, z^{e}\right)$ associated with scheme $S^{\prime}$ ? Let $U^{a}=\left\{\left(U_{1}^{a}, \cdots, U_{n}^{a}\right): U_{i}^{a}=u_{i}\left(x_{0}^{a}, x_{i}^{a}, z_{i}^{a}\right), i \in N\right\}$. And let $U^{e}=\left\{\left(U_{1}^{e}, \cdots, U_{n}^{e}\right): U_{i}^{e}=u_{i}\left(x_{0}^{e}, x_{i}^{e}, z_{i}^{e}\right), i \in N\right\}$. From Proposition 1, note that $W\left(U^{e}\right)=0$ under efficiency. When $W\left(U^{a}\right) \geq 0$, then the efficiency cost of a bargaining agreement $\left(x^{a}, y^{a}, z^{a}\right)$ can be measured by

$$
\Delta W^{a}=W\left(U^{a}\right) \geq 0 .
$$

Equation (16) gives $\Delta W^{a}$ as a welfare measure of the distance between the bargaining agreement $\left(x^{a}, y^{a}, z^{a}\right)$ and the Pareto utility frontier. When bargaining leads to efficient outcomes then $\Delta W^{a}=0$ (from Proposition 1). But when bargaining agreements lead to allocations that fall short of efficiency, then $\Delta W^{a}>0$. In this case, Equation (16) provides a basis to evaluate the welfare cost of imperfect bargaining.

Note that there are many ways for society to be inefficient. From Corollary 1 , inefficiency can arise when $x_{i}$ does not satisfy (4), when $y$ does not satisfy (6), when $\left(x_{0}, z\right)$ does not satisfy (7) and/or when the aggregate budget constraint is not binding. Given this complexity, is there a simple way to represent inefficient agreements? The answer is: Yes. Consider the case where imperfections in bargaining can be represented by a bargaining cost $c$. Under bounded rationality, $c$ can be interpreted as the cost of making decisions in a complex situation (Oprea, 2020). The bargaining cost $c$ can provide a rationale for inefficient agreements: bargaining would stop when $\Delta W^{a}<c$, i.e. when the benefit of bargaining is less than its cost. We can introduce this bargaining cost in the evaluation of bargaining agreements by modifying Proposition 4 as stated next. (The proof is similar to Proposition 4 and is omitted).

Proposition 5:

1) If $c \geq W\left(U^{t}\right)$, there is no bargaining agreement and the allocation is the threat point $\left(x^{t}, y^{t}, z^{t}, U^{t}\right)$. 
2) If $0 \leq c<W\left(U^{t}\right)$, consider the optimization problem

$$
\begin{aligned}
& \max _{x, y, z, U}\left\{\prod_{i \in N}\left[b_{i}\left(x_{0}, x_{i}, z_{i}, U_{i}^{t}\right)-b_{i}\left(x_{0}, x_{i}, z_{i}, U_{i}\right)\right]: \sum_{i \in N} b_{i}\left(x_{0}, x_{i}, z_{i}, U_{i}\right) \geq c ;\right. \\
& \left.\sum_{i \in N} x_{i} \leq y ; b_{i}\left(x_{0}, x_{i}, z_{i}, U_{i}^{t}\right) \geq 0, i \in N ; x_{N} \in X^{n} ;\left(x_{0}, y, T-z\right) \in F, U \in \mathcal{U}\right\}
\end{aligned}
$$

which has for solution $\left(x^{b}, y^{b}, z^{b}, U^{b}\right)$. Then, the allocation $\left(x^{b}, y^{b}, z^{b}, U^{b}\right)$ is a bargaining agreement which is efficient if $c=0$ but inefficient if $c>0$.

Proposition 5 proposes a simple representation of inefficient bargaining agreements, conditional on $c$. Equation (17a) states that bargaining fails and will generate the threat allocation $\left(x^{t}, y^{t}, z^{t}, U^{t}\right)$ when bargaining cost is larger than the payoff from bargaining: $c \geq W\left(U^{t}\right)$. And Equation (17b) generalizes (15) by introducing cost $c$. In a way similar to (15), the solution to (17b) is a bargaining agreement (see the proof for Proposition 4). When $c=0$, (17b) reduces to (15), which identifies an efficient bargaining agreement (from Proposition 4). But when $0 \leq c<W\left(U^{t}\right)$, (17b) provides useful information on inefficient bargaining agreements. In general, the solution $\left(x^{b}, y^{b}, z^{b}, U^{b}\right)$ to $(17 \mathrm{~b})$ varies with $c$. Evaluating (17b) for different values of $c \geq 0$ generates a set of bargaining agreements going from an efficient agreement (when $c=0$ ), to inefficient agreements (when $0<c<W\left(U^{t}\right)$ ) and to no agreement (when $c \geq W\left(U^{t}\right)$ ). In this context, $c$ reflects the degree of inefficiency: the agreements represented by (17b) become increasingly inefficient as $c$ increases from 0 to $W\left(U^{t}\right)$. Interpreting $c$ as the cost of making decisions in a complex situation, our analysis sheds light on the joint analysis of bargaining and efficiency under bounded rationality: As the bargaining scheme $S$ ' generates a unique point on the Pareto utility frontier (from Propositions 3 and 4), combining bargaining and efficiency settles the issue of how welfare is distributed within society. But scheme $\mathrm{S}$ opens the possibility that bargaining does not always lead to efficient outcomes under bounded rationality, and this inefficiency can be reflected by the bargaining cost cin Proposition 5.

\section{Threat Points}

What determines the threat allocations $\left(x_{0 i}^{t}, x_{i}^{t}, y_{i}^{t}, z_{i}^{t}\right)$ and associated utilities $U_{i}^{t}, i \in N$ ? These threats are the outcomes obtained under bargaining failure. In general, the occurrence and nature of bargaining failures depend on the socio-economic and political context. In this section, we discuss several alternative approaches to evaluate threat strategies.

A first approach involves the extreme situation where bargaining failure occurs in all aspects of society. In this case, the threats would correspond to breaking up society into $n$ parts, each individual managing his/her resources independently. Since in this approach each decision is made entirely at the individual level, the characterization of bargaining failure would be simple: the threat points $\left(x_{0 i}^{t}, x_{i}^{t}, y_{i}^{t}, z_{i}^{t}\right)$ would be the outcomes obtained from applying the anal- 
ysis presented above to each individual, $i \in N$.

A second approach associates the threats to non-cooperative behavior within society. In this case, building on the work of Nash $(1950,1953)$, the threat points could be identified as equilibrium points in a non-cooperative game played by the $n$ individuals (e.g., Rubinstein, 1982; Osborne \& Rubinstein, 1990; Binmore et al., 1992). This approach captures strategic interactions existing among individuals within market as well as non-market institutions. But it faces two challenges. First, the nature of these interactions can be complex as many coalitions can form, with each individual possibly joining multiple coalitions in the bargaining process (Harsanyi, 1977). Second, dealing with the role of asymmetric and incomplete information in non-cooperative games remains difficult (Binmore et al., 1992).

A third approach involves the role of social rules and their effects on resolving conflicts and limiting the cost of bargaining failure within society. Such social rules can be formal as well as informal. Formal rules are set by local, state and international institutions, and they guide and constrain socio-economic and political behavior. Such rules also involve the Courts that can step in when disputes cannot be resolved through private bargaining. The Courts system is a specialized disputes-settling institution whose existence is justified by the high frequency of bargaining failure in our modern society.

Informal social rules which reflect the social nature of human beings are also important. Each individual typically belongs to many social networks, where each social network develops behavioral rules that can guide social interactions and individual behavior. The household is a good example of a social institution where informal rules help manage social interactions among its members (e.g., Ellickson, 2008). In general, social rules play a role when conflicts arise between individuals within a group. When social networks help manage and reduce conflicts, they can also limit the effects of bargaining failure on individual welfare. In this case, informal social rules would also affect the threat points used in our analysis.

In general, we expect threat points to depend on the social and political institutions that impact the conflict resolution mechanisms in each specific context. We explore next the importance of threat points and their effects on income distribution.

\section{Bargaining and Welfare Distribution}

How does the bargaining outcome relate to welfare distribution in society? From Equations (9)-(11), our definition of a bargaining agreement relies on the benefit function $b_{i}\left(x_{0}, x_{i}, z_{i}, U_{i}^{t}\right)$ in (3). How does this benefit function relate to income distribution? To answer this question, we will make use of the following result.

Lemma 1: Assuming that $b_{i}\left(x_{0}, x_{i}, z_{i}, U_{i}\right)$ is absolutely continuous in $U_{i}$, we have 


$$
b_{i}\left(x_{0}, x_{i}^{c}, z_{i}, U_{i}^{t}\right)=e_{i}\left(p, x_{0}, z_{i}, u_{i}\left(x_{0}, x_{i}^{c}, z_{i}\right)\right)-e_{i}\left(p, x_{0}, z_{i}, U_{i}^{t}\right) .
$$

where $x_{i}^{c}$ is the Hicksian demand function satisfying

$x_{i}^{c}\left(p, x_{0}, z_{i}, U_{i}\right) \in \arg \min _{x_{i}}\left\{p x_{i}: u_{i}\left(x_{0}, x_{i}, z_{i}\right) \geq U_{i}, x_{i} \in X_{i}\right\}, i \in N$.

Equation (18) establishes a relationship between $b_{i}\left(x_{0}, x_{i}^{c}, z_{i}, U_{i}^{t}\right)$ and the expenditure function $e_{i}\left(p, x_{0}, z_{i}, U_{i}\right)$ defined in (5). In turn, let $x_{i}^{M}\left(p, x_{0}, z_{i}, w_{i}\right)$ be the Marshallian demand function that solves the utility maximization problem $V_{i}\left(p, x_{0}, z_{i}, w_{i}\right)=\max _{x_{i}}\left\{u_{i}\left(x_{0}, x_{i}, z_{i}\right): p x_{i} \leq w_{i}, x_{i} \in X_{i}\right\}$ where $w_{i}$ is the income allocated to the $i$-th individual and $V_{i}\left(p, x_{0}, z_{i}, w_{i}\right)$ is the associated indirect utility function, $i \in N$. By duality, we have $x_{i}^{c}\left(p, x_{0}, z_{i}, U_{i}\right)=x_{i}^{M}\left(p, x_{0}, z_{i}, e_{i}\left(p, x_{0}, z_{i}, U_{i}\right)\right)$ and $e_{i}\left(p, x_{0}, z_{i}, V_{i}\left(p, x_{0}, z_{i}, w_{i}\right)\right)=w_{i}$ (e.g., Deaton \& Muellbauer, 1980), making it clear that the expenditure function $e_{i}\left(p, x_{0}, z_{i}, U_{i}\right)$ measures the purchasing power of the $i$-th individual, $i \in N$, conditional on $\left(p, x_{0}, z_{i}, U_{i}\right)$.

In this context, the distribution of purchasing power in society can be measured by the expenditure share

$$
S_{i}(p, x, z)=\frac{e_{i}\left(p, x_{0}, z_{i}, u_{i}\left(x_{0}, x_{i}, z_{i}\right)\right)}{\sum_{j \in N} e_{j}\left(p, x_{0}, z_{j}, u_{j}\left(x_{0}, x_{j}, z_{j}\right)\right)} \in[0,1], i \in N .
$$

The expenditure share $S_{i}(p, x, z)$ in (19) reflects the distribution of income in society: $S_{i}(p, x, z)$ being large (small) means that the $i$-th individual receives a large (small) share of aggerate income. What are the implications of a bargaining agreement for welfare distribution? Using Equations (9)-(11) and (18), a bargaining agreement implies that

$b_{i}\left(x_{0}, x_{i}^{c}, z_{i}, U_{i}^{t}\right)=e_{i}\left(p, x_{0}, z_{i}, u_{i}\left(x_{0}, x_{i}^{c}, z_{i}\right)\right)-e_{i}\left(p, x_{0}, z_{i}, U_{i}^{t}\right)=k$ for some $k$ for all $i \in N$. It follows that

$e_{i}\left(p, x_{0}, z_{i}, u_{i}\left(x_{0}, x_{i}^{c}, z_{i}\right)\right)$

$=e_{i}\left(p, x_{0}, z_{i}, U_{i}^{t}\right)+\sum_{j \in N}\left[e_{j}\left(p, x_{0}, z_{j}, u_{j}\left(x_{0}, x_{j}^{c}, z_{j}\right)\right)-e_{j}\left(p, x_{0}, z_{j}, U_{j}^{t}\right)\right] / n$, im-

plying that expression (19) can be alternatively written as

$$
S_{i}(p, x, z)=\frac{1}{n}+\frac{e_{i}\left(p, x_{0}, z_{i}, U_{i}^{t}\right)-\left[\sum_{j \in N} e_{j}\left(p, x_{0}, z_{j}, U_{j}^{t}\right) / n\right]}{\sum_{j \in N} e_{j}\left(p, x_{0}, z_{j}, u_{j}\left(x_{0}, x_{j}^{c}, z_{j}\right)\right)} \in[0,1], i \in N .
$$

Equation (20) indicates how the expenditure share $S_{i}$ of the $i$-th individual depends on the threat points $\left(U_{1}^{t}, \cdots, U_{n}^{t}\right)$. It implies that $S_{i}(p, x, z)\left\{\begin{array}{l}> \\ = \\ <\end{array}\right\} \frac{1}{n}$ when $e_{i}\left(p, x_{0}, z_{i}, U_{i}^{t}\right)\left\{\begin{array}{l}> \\ = \\ <\end{array}\right\} \sum_{j \in N} e_{j}\left(p, x_{0}, z_{j}, U_{j}^{t}\right) / n$. Thus, under a bargaining agreement, all individuals would have equal private expenditures if they face the same expenditure $e_{i}\left(p, x_{0}, z_{i}, U_{i}^{t}\right)$ under the threat point $U_{i}^{t}$. Alternatively, Equation (20) shows how unequal relative distribution of purchasing power can 
arise when the threat expenditures $e_{i}\left(p, x_{0}, z_{i}, U_{i}^{t}\right)$ vary across individuals. Individuals who have a high $e_{i}\left(p, x_{0}, z_{i}, U_{i}^{t}\right)$ would have high relative purchasing power $S_{i}(p, x, z)$. Alternatively, individuals who have a low $e_{i}\left(p, x_{0}, z_{i}, U_{i}^{t}\right)$ would have low relative purchasing power $S_{i}(p, x, z)$. Thus, our analysis applies to a wide range of income distributions: depending on the purchasing power of each individual at the threat points, income distribution can vary from egalitarian to very unequal. In general, noting that $e_{i}\left(p, x_{0}, z_{i}, U_{i}^{t}\right)$ is increasing in $U_{i}^{t}$, a ceteris paribus increase (decrease) in the threat point $U_{i}^{t}$ would increase (decrease) the $i$-th individual's private expenditure share $S_{i}(p, x, z)$. Interpreting this expenditure share as a measure of relative welfare in society shows how the threat points affect relative welfare. Individuals who face limited threat from bargaining failure get a higher share of aggregate income.

\section{Implications}

This section explores the implications of our analysis. In particular, we evaluate the role of preferences and their effects on bargaining outcomes. We also discuss the possible decentralization of economic and political institutions and the role of public goods.

\subsection{The Role of Preferences}

Our analysis of a bargaining agreement relies on the willingness-to-pay measured by $b_{i}\left(x_{0}, x_{i}, z_{i}, U_{i}^{t}\right), i \in N$. From Equation (3), this willingness-to-pay measure depends on individual preferences. Thus, we expect bargaining agreements to be influenced by the nature of individual preferences. What is the role of preferences in the bargaining process? Given $U_{i}^{t}=u_{i}\left(x_{0}^{t}, x_{i}^{t}, z_{i}^{t}\right)$, the answer to this question depends on how preferences affect $b_{i}\left(x_{0}, x_{i}, z_{i}, u_{i}\left(x_{0}^{t}, x_{i}^{t}, z_{i}^{t}\right)\right)$. This gives two important insights. First, both the current allocation $\left(x_{0}, x_{i}, z_{i}\right)$ and the threat allocation $\left(x_{0}^{t}, x_{i}^{t}, z_{i}^{t}\right)$ play a role. Second, the impact of preferences on bargaining is driven by their effects on the term

$b_{i}\left(x_{0}, x_{i}, z_{i}, u_{i}\left(x_{0}^{t}, x_{i}^{t}, z_{i}^{t}\right)\right)$, which depends on the shape of preferences as well as preferences' valuations at the current and threat allocations. Generally, a ceteris paribus change in individual is preferences would strengthen his/her bargaining position if the change reduces $b_{i}\left(x_{0}, x_{i}, z_{i}, u_{i}\left(x_{0}^{t}, x_{i}^{t}, z_{i}^{t}\right)\right)$, as this would make individual $i$ less willing to make a concession. Alternatively, a preference change would weaken the bargaining position of individual $i$ when it induces an increase in $b_{i}\left(x_{0}, x_{i}, z_{i}, u_{i}\left(x_{0}^{t}, x_{i}^{t}, z_{i}^{t}\right)\right)$, as this would make individual $i$ more willing to make a concession.

Recall that our model represents a general economy. As in Debreu (1959), our approach applies to intertemporal allocations (in which case $(x, y, z)$ represent current as well as future allocations within some planning horizon) and it applies under uncertainty (in which case the allocations $(x, y, z)$ are defined to be state-contingent). In this context, our analysis can evaluate the role of impatience and the role of risk aversion. 
First, consider the effects of impatience on bargaining (Rubinstein, 1982). The role of impatience arises whenever the benefits occur in the future. Then, the current evaluation of an agreement depends on the intertemporal preferences which reflect how individuals discount future benefits. And different individuals could discount the future at different rates, with "more patient" individuals have a lower discount rate while "more impatient" individuals have a higher discount rate (Rubinstein, 1982). Our analysis shows that the effects of patience (or impatience) on bargaining strength depend on each specific situation. On the one hand, the $i$-th individual becoming more patient would strengthen his/her bargaining position when this change decreases $b_{i}\left(x_{0}, x_{i}, z_{i}, u_{i}\left(x_{0}^{t}, x_{i}^{t}, z_{i}^{t}\right)\right)$, thus reducing his/her willingness to make a concession. This would occur when bargaining failure allocates relatively more benefits to the future, compared with the current allocation, thus associating greater patience with a decline in ex ante willingness to pay to avoid a bargaining failure. But greater patience would instead weaken the bargaining position of individual $i$ if it induces an increase in $b_{i}\left(x_{0}, x_{i}, z_{i}, u_{i}\left(x_{0}^{t}, x_{i}^{t}, z_{i}^{t}\right)\right)$, as this would make individual $i$ more willing to make a concession. This would occur when bargaining failure has large adverse effects on future benefits, thus associating greater patience with an increase in ex ante willingness to pay to avoid a bargaining failure. Note that this result differs from the one obtained by Rubinstein (1982). The reason is that, in our model, the bargaining position of each individual is evaluated in relative terms, i.e. compared with threat points.

Similar arguments apply to the effects of risk preferences. When benefits are uncertain, the willingness-to-pay measures $b_{i}\left(x_{0}, x_{i}, z_{i}, U_{i}\right)$ are ex ante measures. For risk averse individuals, willingness-to-pay would decline when benefits become more uncertain. In this context, one expects bargaining to be affected by both risk exposure and risk aversion (e.g., Murnighan et al., 1988). How does a ceteris paribus change in risk aversion affect the outcome of the bargaining process? Again, the answer depends on the specific situation. If bargaining failure involves higher individual risk exposure compared with the current allocation, then greater risk aversion is associated with a rise in ex ante willingness to pay to avoid a bargaining failure. In this case, the $i$-th individual becoming more risk averse would weaken his/her bargaining position as this change raises $b_{i}\left(x_{0}, x_{i}, z_{i}, u_{i}\left(x_{0}^{t}, x_{i}^{t}, z_{i}^{t}\right)\right)$, thus increasing his/her willingness to make a concession. In the opposite case, if bargaining failure reduces individual risk exposure compared with the current allocation, greater risk aversion could instead strengthen the bargaining position of individual $i$. These results reflect that the effects of risk aversion depend on the patterns of risk exposure that can vary between the current allocation and the threat allocation.

\subsection{Decentralization}

Our analysis sheds light on the institutions supporting the bargaining process in society. An important issue is the role of markets in supporting decentralized 
resource allocations. To discuss this issue, it will be convenient for us to examine the special case where $x_{0}=0$, i.e. where no public goods are provided. The role of public goods will be evaluated in the next sub-section. Given $x_{0}=0$, the analysis of efficiency then reduces to investigating the allocation choice $\left(x_{1}, \cdots, x_{n}, y, z_{1}, \cdots, z_{n}\right)$. In a market economy, efficiency would be given in Corollary 1 with one exception: conditional on $x_{0}=0$, Equation (7) would become

$$
W_{0}(U)=\min _{p \geq 0} \max _{z}\left\{\pi(p, 0, z)-\sum_{i \in N} e_{i}\left(p, 0, z_{i}, U_{i}\right): z \in Z^{n}\right\} .
$$

Then, Equations (5) And (6) and ( $\left.7^{\prime}\right)$ along with $W_{0}(U)=0$ provide a representation of an economy supporting an efficient allocation of private goods (conditional on $x_{0}=0$ ). This corresponds to the standard welfare theorems establishing close linkages between efficiency and competitive markets (e.g., Debreu, 1959). Indeed, under competitive markets, Equation (5) states that consumers minimize expenditures; Equation (6) is a profit maximization condition for production decisions; and Equation ( $\left.7^{\prime}\right)$ states that time allocation $z=\left(z_{1}, \cdots, z_{n}\right)$ is efficient and prices $p$ clear the markets for private goods. In this case, competitive prices support an efficient allocation of private goods. From Equation (5), the consumption decisions are decentralized: each consumer makes consumption decisions in response to market prices $p, i \in N$. And when production decisions are made by multiple firms with the absence of externalities, the profit maximization condition (6) would apply at the firm level, meaning that profit-maximizing competitive firms would produce efficient outputs. This is Adam Smith's (1776) "invisible hand" where competitive market prices guide decentralized decision making for both producers and consumers to support an efficient allocation.

Our analysis goes beyond the standard welfare theorems in two ways. First, it allows for inefficiency. The inefficiency could apply to any good in $\left(x_{1}, \cdots, x_{n}, y, z_{1}, \cdots, z_{n}\right)$, involving consumption decisions $\left(x_{1}, \cdots, x_{n}\right)$ (when such decisions do not satisfy (5)), production decisions $y$ (when such decisions do no maximize aggregate profit in (6)) and/or time allocation (when the choice of $z$ does not satisfy (7)). Inefficient outcomes are the allocations located below the Pareto utility frontier. As discussed above, inefficiency could arise because of the limited cognitive abilities of decision makers. One advantage of competitive markets is their reliance on price signals to guide producers and consumers toward efficiency, thus greatly reducing the need for information about the extent of resource scarcity and/or the preferences of all members of society. But this argument becomes weaker when applied to time allocation. The efficient allocation of time $z=\left(z_{1}, \cdots, z_{n}\right)$ given in (7) depends on leisure preferences, on the productivity of labor and the ability to match labor supply with labor demand. Heterogeneities in leisure preferences and labor productivity across individuals along with search cost make the matching of supply and demand in the labor market challenging. This is a scenario where imperfections in the labor market can generate unemployment, generating a debate about whether markets alone can sup- 
port an efficient economy (e.g., Keynes, 1936). By allowing for inefficiency (including inefficiency in the labor market), our analysis provides a basis to address these issues.

Second, our approach goes beyond the welfare theorems by investigating the linkages between bargaining and distribution issues. Pareto efficiency does not provide guidance about the evaluation of income distribution, but our bargaining model does. There are more than one points along the Pareto frontier, but there is only one unique point which is both efficient and a bargaining agreement. Bargaining agreements can be inefficient in general, but each move towards the Pareto frontier in the bargaining scheme improves efficiency. This illustrates how a joint analysis of bargaining and efficiency provides new insights on the tradeoff between efficiency and distribution issues.

\subsection{The Role of Public Goods}

What is the role of public goods in resource allocation? From Corollary 1, the efficient choice of public goods $x_{0}$ is given in Equation (7), stating that the efficient $x_{0}$ occurs when the aggregate net benefit is maximized (where the aggregate benefit is given by $\left.\left[\pi\left(p, x_{0}, z\right)-\sum_{i \in N} e_{i}\left(p, x_{0}, z_{i}, U_{i}\right)\right]\right)$. Assuming that $0 \in X_{0}$, comparing (7) and (7') implies that $W(U) \geq W_{0}(U)$. This follows from the fact that $\left(7^{\prime}\right)$ is a constrained version of (7): the restriction $X_{0}=0$ is imposed in ( $\left.7^{\prime}\right)$ but not in (7). Therefore, a measure of the aggregate welfare loss due to a failure to invest in public goods is given by

$$
\Delta W \equiv W(U)-W_{0}(U) \geq 0 .
$$

When the public goods affect many individuals, decentralized decision making might no longer support an efficient allocation. Some form of coordination scheme is then needed, which can be provided by centralized institutions. Consider the case where there are positive benefits from the public goods, i.e. where $\Delta W>0$. In this case, society benefits from investment in the public goods $x_{0}$. But two questions remain: First, is the choice of $x_{0}$ efficient? Second, is the distribution of the associated benefits acceptable to society members so that it can support a bargaining agreement? Evaluating the efficiency of public goods is equivalent to investigating whether $x_{0}$ satisfies Equation (7). And assessing the acceptability of an agreement is equivalent to examining whether Equations (10) and (11) are satisfied. Therefore, having positive benefits from providing public goods is not sufficient to support a bargaining agreement: both efficiency and distribution issues play a role in the economic assessment of investments in public goods.

Our analysis provides useful insights into the economics of public goods. Under our framework, the collective action supporting the provision of public goods is likely to be successful under three conditions: 1) the aggregate benefit $\Delta W$ is large; 2) the provision of the public goods is efficiently administered; and 3) the benefits are distributed to satisfy Equations (10) and (11). When all three 
conditions are satisfied, we expect to see strong political support for collective action. But a failure to satisfy any of the three conditions is sufficient to undermine the support for associated policies. Condition 1) would be satisfied when public goods generate significant benefits to many members of society (e.g., investment in infrastructure); but it is less likely to be satisfied for "local public goods" that benefit only a few individuals. In the latter case, potential bargaining leading to an efficient allocation can be hindered by bargaining cost. Condition 2) would not be satisfied when the provision of public goods is not well administered. This would include situations of "rent seeking" behavior (Krueger, 1974) and poor governance or corruption (Rose-Ackerman, 1975). Such situations would reduce the perceived benefits of providing public goods and thus weaken the political support for associated policies. Finally, condition 3) may not be satisfied in the presence of large income and welfare inequalities that could motivate individuals to reject a bargaining agreement on the basis of welfare distribution. Hence, how individuals perceive their welfare situation compared to the threat points matter. And this stresses the importance of these threat points in the evaluation of bargaining and political agreements.

\section{Conclusion}

This paper has investigated the economics of resource allocation and welfare distribution under general conditions. The analysis generalizes the Nash-Harsanyi bargaining model: it applies under ordinal preferences and under bounded rationality. The approach relies on evolutionary schemes where each step represents the bargaining process among all individuals in society. At each step, each individual's willingness to make a concession depends on the relative perceived cost of bargaining failure. In this context, we show how the bargaining process converges to a bargaining agreement. Under bounded rationality, the bargaining agreement can be inefficient, in which case our analysis provides a measure of the economic cost of inefficiency. We also show how bargaining agreements can be efficient and converge to a unique point on the Pareto utility frontier. In all cases, we show how bargaining agreements can be represented by the maximization of a "generalized Nash product". We also investigate the implications of threat points (representing bargaining failure) for welfare distribution. Whether or not efficiency is achieved, we explore the linkages between threat points and welfare distribution, showing how the relative bargaining power of individuals affects income distribution. We also discuss the role of decentralization and public goods, and of markets as well as non-market institutions as they affect the efficiency of resource allocation and associated welfare distribution.

We stress the generality of our approach: it allows for private goods as well as public goods; and it applies to bargaining under bounded rationality. We see introducing bounded rationality as an important contribution: it helps make economic modeling more realistic (reflecting cognitive difficulties often faced by individuals involved in the process of economic and political bargaining). We 
also see the joint analysis of efficiency and distribution issues as another important contribution. Finally, in the presence of public goods, our analysis provides useful insights into the role of markets, management and government policy in global markets.

While our approach applies under general conditions, further refinements are possible. First, the management of bargaining failures needs more attention. In the presence of strong linkages between threat points and welfare distribution, the design and implementation of conflict resolution mechanisms need further investigations. Second, the analysis presented in this paper is theoretical. Further research is needed to explore applications of our approach to economic and policy decisions.

\section{Acknowledgements}

The research was funded in part through financial support from the Graduate School, University of Wisconsin, Madison.

\section{Conflicts of Interest}

The authors declare no conflicts of interest regarding the publication of this paper.

\section{References}

Binmore, K., Osborne, M. J., \& Rubinstein, A. (1992). Noncooperative Models of Bargaining. In Handbook of Game Theory with Economic Applications (Vol. 1, pp. 179-225). Elsevier. https://doi.org/10.1016/S1574-0005(05)80010-4

Binmore, K., Rubinstein, A., \& Wolinsky, A. (1986). The Nash Bargaining Solution in Economic Modelling. The RAND Journal of Economics, 17, 176-188.

https://doi.org/10.2307/2555382

Chatterjee, K., Dutta, B., Ray, D., \& Sengupta, K. (1993). A Noncooperative Theory of Coalitional Bargaining. The Review of Economic Studies, 60, 463-477. https://doi.org/10.2307/2298067

Chavas, J. P. (2015). Coase Revisited: Economic Efficiency under Externalities, Transaction Costs and Non-Convexity. Journal of Institutional and Theoretical Economics, 171, 709-734. https://doi.org/10.1628/093245615X14363478578775

Chavas, J. P., \& Wang, R. (2021). Evolutionary Economics under Nonconvexity and Externalities. Oxford Economic Papers, 73, 1369-1389. https://doi.org/10.1093/oep/gpab020

Coase, R. H. (1960). The Problem of Social Cost. Journal of Law and Economics, 3, 1-44. https://doi.org/10.1086/466560

Compte, O., \& Jehiel, P. (2010). The Coalitional Nash Bargaining Solution. Econometrica, 78, 1593-1623. https://doi.org/10.3982/ECTA7883

Crockett, S., Oprea, R., \& Plott, C. (2011). Extreme Walrasian Dynamics: The Gale Example in the Lab. American Economic Review, 101, 3196-3220. https://doi.org/10.1257/aer.101.7.3196

Deaton, A., \& Muellbauer, J. (1980). Economics and Consumer Behavior. Cambridge University Press. https://doi.org/10.1017/CBO9780511805653 
Debreu, G. (1959). The Theory of Value: An Axiomatic Analysis of Economic Equilibrium. Wiley.

Ellickson, R. C. (2008). The Household: Informal Order around the Hearth. Princeton University Press.

Forges, F., Mertens, J. F., \& Vohra, R. (2002). The Ex-Ante Incentive Compatible Core in the Absence of Wealth Effects. Econometrica, 70, 1865-1892. https://doi.org/10.1111/1468-0262.00356

Gintis, H. (2007). The Dynamics of General Equilibrium. The Economic Journal, 117, 1280-1309. https://doi.org/10.1111/j.1468-0297.2007.02083.x

Hanany, E., \& Safra, Z. (2000). Existence and Uniqueness of Ordinal Nash Outcomes. Journal of Economic Theory, 90, 254-276. https://doi.org/10.1006/jeth.1999.2601

Harsanyi, J. C. (1950). Approaches to the Bargaining Problem before and after the Theory of Games: A Critical Discussion of Zeuthen's Hicks's and Nash's Theories. Econometrica, 24, 144-157. https://doi.org/10.2307/1905748

Harsanyi, J. C. (1963). A Simplified Bargaining Model for the n-Person Cooperative Game. International Economic Review, 4, 194-220. https://doi.org/10.2307/2525487

Harsanyi, J. C. (1977). Rational Behavior and Bargaining Equilibrium in Games and Social Situations. Cambridge University Press. https://doi.org/10.1017/CBO9780511571756

Keynes, J. M. (1936). The General Theory of Employment, Interest and Money. Macmillan Cambridge University Press.

Krueger, A. O. (1974). The Political Economy of the Rent-Seeking Society. American Economic Review, 64, 291-303.

Luenberger, D. G. (1992). Benefit Functions and Duality. Journal of Mathematical Economics, 21, 461-481. https://doi.org/10.1016/0304-4068(92)90035-6

Mandel, A., \& Gintis, H. (2016). Decentralized Pricing and the Equivalence between Nash and Walrasian Equilibrium. Journal of Mathematical Economics, 63, 84-92.

https://doi.org/10.1016/j.jmateco.2015.12.008

Milanovic, B. (2013). Global Income Inequality in Numbers: In History and Now. Global Policy, 4, 198-208. https://doi.org/10.1111/1758-5899.12032

Murnighan, J. K., Roth, A. E., \& Schoumaker, F. (1988). Risk Aversion in Bargaining: An Experimental Study. Journal of Risk and Uncertainty, 1, 101-124.

https://doi.org/10.1007/BF00055566

Nash, J. F. (1950). The Bargaining Problem. Econometrica, 18, 155-162.

Nash, J. F. (1953). Two-Person Cooperative Games. Econometrica, 21, 128-140. https://doi.org/10.2307/1906951

Oprea, R. (2020). What Makes Rules Complex? American Economic Review, 110, 3913-3951. https://doi.org/10.1257/aer.20191717

Osborne, M. J., \& Rubinstein, A. (1990). Bargaining and Markets. Academic Press.

Ostrom, E. (2000). Collective Action and the Evolution of Social Norms. Journal of Economic Perspectives, 14, 137-158. https://doi.org/10.1257/jep.14.3.137

Piketty, T. (2014). Capital in the Twenty-First Century. Harvard University Press. https://doi.org/10.4159/9780674369542

Radner, R. (1968). Competitive Equilibrium under Uncertainty. Econometrica, 36, 31-58. https://doi.org/10.2307/1909602

Rose-Ackerman, S. (1975). The Economics of Corruption. Journal of Public Economics, 
4, 187-203. https://doi.org/10.1016/0047-2727(75)90017-1

Rubinstein, A. (1982). Perfect Equilibrium in a Bargaining Model. Econometrica, 50, 97-109. https://doi.org/10.2307/1912531

Rubinstein, A. (1998). Modeling Bounded Rationality. Zeuthen Lecture Book Series, MIT Press. https://doi.org/10.7551/mitpress/4702.001.0001

Rubinstein, A., Safra, Z., \& Thomson, W. (1992). On the Interpretation of the Nash Bargaining Solution and Its Extension to Non-Expected Utility Preferences. Econometrica, 60, 1171-1186. https://doi.org/10.2307/2951543

Sandholm, W. H. (2010). Population Games and Evolutionary Dynamics. MIT Press.

Simon, H. (1955). A Behavioral Model of Rational Choice. Quarterly Journal of Economics, 69, 99-118.

Smith, A. (1776). An Inquiry into the Nature and Causes of the Wealth of Nations. W. Strahan. https://doi.org/10.1093/oseo/instance.00043218

Takayama, A. (1985). Mathematical Economics. Cambridge University Press.

Vega-Redondo, F. (1997). The Evolution of Walrasian Behavior. Econometrica, 65, 375-384. https://doi.org/10.2307/2171898

Zeuthen, F. (1930). Problems of Monopoly and Economic Warfare. Routledge \& Kegan Paul. 


\section{Appendix: Proofs}

Proof of Proposition 1.

Consider a feasible point $\left(x^{*}, y^{*}, z^{*}, \beta^{*}, U^{*}\right)$ that satisfies Equations (1) and (2), where $U_{i}^{*}=u_{i}\left(x_{0}^{*}, x_{i}^{*}, z_{i}^{*}\right), i \in N$. Assume that the allocation $\left(x^{*}, y^{*}, z^{*}\right)$ is not efficient. It means that there exists another feasible allocation $\left(x^{0}, y^{0}, z^{0}\right)$ such that $u_{i}\left(x_{0}^{0}, x_{i}^{0}, z_{i}^{0}\right) \geq u_{i}\left(x_{0}^{*}, x_{i}^{*}, z_{i}^{*}\right)=U_{i}^{*}$ for all $i \in N$ and $u_{j}\left(x_{0}^{0}, x_{j}^{0}, z_{i}^{0}\right)>u_{j}\left(x_{0}^{*}, x_{j}^{*}, z_{j}^{*}\right)=U_{j}^{*}$ for some individual $j \in N$. Let $b_{i}\left(x_{0}, x_{i}, z_{i}, U_{i}^{*}\right) \equiv \max _{\beta_{i}}\left\{\beta_{i}: u_{i}\left(x_{0}, x_{i}-\beta_{i} g, z_{i}\right) \geq U_{i}^{*}\right\}, i \in N$. Under Equations (1) and (2), we have $b_{i}\left(x_{0}^{*}, x_{i}^{*}, z_{i}^{*}, U_{i}^{*}\right)=0, i \in N$. Under assumptions As1 (continuity), As2 (strict monotonicity) and As4 (no destitution), $u_{i}\left(x_{0}^{0}, x_{i}^{0}, z_{i}^{0}\right) \geq U_{i}^{*}$ implies that $b_{i}\left(x_{0}^{0}, x_{i}^{0}, z_{i}^{0}, U_{i}^{*}\right) \geq 0, i \in N$, and $u_{j}\left(x_{0}^{0}, x_{j}^{0}, z_{j}^{0}\right)>U_{j}^{*}$ implies that $b_{j}\left(x_{0}^{0}, x_{j}^{0}, z_{j}^{0}, U_{j}^{*}\right)>0$. Note that feasibility is maintained as $\sum_{i \in N} x_{i}^{0} \leq y^{0}$ implies $\sum_{i \in N}\left[x_{i}^{0}-b_{i}\left(x_{0}^{0}, x_{i}^{0}, z_{i}^{0}, U_{i}^{*}\right) g\right] \leq y^{0}$. Thus, we have

$\sum_{i \in N} b_{i}\left(x_{0}^{0}, x_{i}^{0}, z_{i}^{0}, U_{i}^{*}\right)>0$, which contradicts that $\left(x^{*}, y^{*}, z^{*}\right)$ is a solution to Equations (1) and (2). That is, if $U^{*}$ satisfies (2), then $\left(x^{*}, y^{*}, z^{*}\right)$ is not the willingness-to-pay maximizer in (1); or $U^{*}$ does not satisfy (2). Therefore, Equations (1) and (2) imply efficiency.

Now consider a feasible allocation $\left(x^{a}, y^{a}, z^{a}\right)$ that is efficient. Assume that it does not satisfy Equations (1) and (2). This can happen in two ways. First, it can happen if $\left(x^{a}, y^{a}, z^{a}, \beta^{a}, U^{a}\right)$ does not satisfy Equation (1), i.e. if there exists a feasible point $\left(x^{d}, y^{d}, z^{d}, \beta^{d}\right) \neq\left(x^{a}, y^{a}, z^{a}, \beta^{a}\right)$ such that $D \equiv \sum_{i \in N} \beta_{i}^{d}-\sum_{i \in N} \beta_{i}^{a}>0$. Under assumption As2, redistributing $D$ units of the private bundle $g$ to the $n$ individuals can make at least one person better off without making anyone worse off, contradicting efficiency. Second, it can happen if $\left(x^{a}, y^{a}, z^{a}, \beta^{a}, U^{a}\right)$ does not satisfy Equation (2), i.e. if $\sum_{i \in N} \beta_{i}^{a} \neq 0$. Note that the feasibility conditions $\left\{u_{i}\left(x_{0}^{a}, x_{i}^{a}, z_{i}^{a}\right) \geq U_{i}^{a}, i \in N\right\}$ in (1) imply that $\sum_{i \in N} \beta_{i}^{a} \geq 0$. But under assumption As2, having $B^{a} \equiv \sum_{i \in N} \beta_{i}^{a}>0$ means that $B^{a}$ units of the private bundle $g$ can be redistributed to the $n$ individuals to make at least one person better off without making anyone worse off, contradicting efficiency. It follows that efficiency implies Equations (1) and (2).

Proof of Corollary 1.

Under assumption As3 (stating that the set $Y\left(x_{0}, z\right)$ is convex), the constrained maximization problem in (1) can be written in terms of the associated Lagrangian $L(x, y, z)=\sum_{i \in N} \beta_{i}+p\left[y-\sum_{i \in N} x_{i}\right]$ where $p y=\sum_{j=1}^{m} p_{j} y_{j}$ and $p \in \mathbb{R}_{+}^{m}$ is a vector of Lagrange multipliers associated with the constraints $\sum_{i \in N} x_{i} \leq y$. Then the optimization problem (1) can be alternatively written as the following saddle-point problem (Takayama, 1985):

$$
\sum_{i \in N} \beta_{i}+p^{*}\left[y-\sum_{i \in N} x_{i}\right] \leq W(U) \equiv \sum_{i \in N} \beta_{i}^{*} \leq \sum_{i \in N} \beta_{i}^{*}+p\left[y^{*}-\sum_{i \in N} x_{i}^{*}\right],
$$

for any $(x, y, z, p)$ satisfying $u_{i}\left(x_{0}, x_{i}-\beta_{i} g, z_{i}\right) \geq U_{i}, \quad i \in N,\left(x_{0}, y, T-z\right) \in F$, $x \in X, \beta \in \mathbb{R}^{n}$ and $p \in \mathbb{R}_{+}^{m}$, where the Lagrange multipliers $p^{*}$ are market clearing prices for private goods. 
Equations (3)-(7) follow from a stage-wise decomposition of the saddle-point problem in (A1). Under Assumptions As1-As3 and choosing $g$ to satisfy $p g=1$, the proof of the equivalence of Equations (4) and (5) is presented in Luenberger (1992: p. 472-474). Finally, Equation (8) is Equation (2).

\section{Proof of Proposition 2:}

When $N^{k} \neq N$, Equations (13a)-(13b) in S3b imply that $M^{k+1}<M^{k}$, i.e. that the maximum willingness-to-pay to avoid bargaining failure declines across iterations from $k$ to $k+1$. Thus, the bargaining process given in $\mathrm{S}$ moves in the direction of equalizing the willingness to accept a bargaining failure. Upon convergence, from S3a, the iterative scheme in $\mathrm{S}$ leads to a point where $N^{k^{\#}}=N$. From definition 2, this identifies $\left(x^{k^{\#}}, y^{k^{\#}}, z^{k^{\#}}\right)$ as a bargaining agreement.

Proof of Proposition 3:

From Proposition 2, $\left(x^{k^{*}}, y^{k^{*}}, z^{k^{*}}\right)$, is a bargaining agreement. Upon convergence, condition S3a' states that $W\left(U^{k^{*}}\right)=0$. Under assumptions As1-As3, Proposition 1 implies that $U^{k^{*}}$ is on the Pareto utility frontier. This implies that the allocation $\left(x^{k^{*}}, y^{k^{*}}, z^{k^{*}}\right)$ is a bargaining agreement that is Pareto efficient.

We now show that this efficient agreement corresponding to a unique point on the Pareto utility frontier. Under assumption As2, note that $W(U)$ is strictly decreasing in $U$. Assume that there are two efficient bargaining agreements $U^{a} \neq U^{d}$ satisfying $W\left(U^{a}\right)=W\left(U^{d}\right)=0 . W(U)$ being strictly decreasing in $U=\left(U_{1}, \cdots, U_{n}\right)$, there must exist some $i \neq j \in N$ such that $u_{i}\left(x_{0}^{a}, x_{i}^{a}, z_{i}^{a}\right)=U_{i}^{a}>U_{i}^{d}=u_{i}\left(x_{0}^{d}, x_{i}^{d}, z_{i}^{d}\right)$ and $u_{j}\left(x_{0}^{a}, x_{j}^{a}, z_{j}^{a}\right)=U_{j}^{a}<U_{j}^{d}=u_{j}\left(x_{0}^{d}, x_{j}^{d}, z_{j}^{d}\right)$. This implies $b_{i}\left(x_{0}^{a}, x_{i}^{a}, z_{i}^{a}, U_{i}^{t}\right)>b_{i}\left(x_{0}^{d}, x_{i}^{d}, z_{i}^{d}, U_{i}^{t}\right)$ and $b_{j}\left(x_{0}^{a}, x_{j}^{a}, z_{j}^{a}, U_{j}^{t}\right)<b_{j}\left(x_{0}^{d}, x_{j}^{d}, z_{j}^{d}, U_{j}^{t}\right)$. But this contradicts the definition of a bargaining agreement in (9)-(11) (stating that all individuals are equally willing to accept a bargaining failure). Thus, $U^{a}=U^{d}$ is the only possibility.

\section{Proof of Proposition 4:}

Under assumption As2, the constraint $\sum_{i \in N} b_{i}\left(x_{0}, x_{i}, z_{i}, U_{i}\right) \geq 0$ is necessarily binding. It follows that the solution to (15) is Pareto efficient and that $U^{e}$ is on the Pareto utility frontier: $U^{e} \in\{U: W(U)=0, U \in \mathcal{U}\}$.

First, consider the case where $b_{i}\left(x_{0}, x_{i}, z_{i}, U_{i}^{t}\right)=0$ for all $i$ and hence $W\left(U^{t}\right)=0$. Then $U^{t}$ is on the Pareto utility frontier and $U^{e}=U^{t}$. Second, consider the case where $W\left(U^{t}\right)>0$. Then, the maximization problem in (15) can be alternatively written as

$$
\begin{aligned}
& \max _{x, y, z, U}\left\{\sum_{i \in N} \ln \left[b_{i}\left(x_{0}, x_{i}, z_{i}, U_{i}^{t}\right)-b_{i}\left(x_{0}, x_{i}, z_{i}, U_{i}\right)\right]: \sum_{i \in N} b_{i}\left(x_{0}, x_{i}, z_{i}, U_{i}\right) \geq 0 ;\right. \\
& \left.\sum_{i \in N} x_{i} \leq y ; x_{N} \in X^{n} ;\left(x_{0}, y, T-z\right) \in F, U \in \mathcal{U}\right\}
\end{aligned}
$$

Under assumption As2, $b_{i}\left(x_{0}, x_{i}, z_{i}, U_{i}\right)$ is decreasing in $U_{i}, i \in N$. Denoting by $\lambda$ the Lagrange multiplier associated with the constraint 
$\sum_{i \in N} b_{i}\left(x_{0}, x_{i}, z_{i}, U_{i}\right) \geq 0$ in $\left(15^{\prime}\right)$, the first-order necessary conditions with respect to $U_{i}$ in $\left(15^{\prime}\right)$ give $\lambda=1 /\left[b_{i}\left(x_{0}, x_{i}, z_{i}, U_{i}^{t}\right)-b_{i}\left(x_{0}, x_{i}, z_{i}, U_{i}\right)\right], i \in N$. Noting that $b_{i}\left(x_{0}, x_{i}, z_{i}, U_{i}\right)=0$ at the optimum, this implies that the solution to (15') satisfies the convergence criterion in S3a', i.e. that the solution to (15) is a bargaining agreement located on the Pareto utility frontier.

Proof of Lemma 1:

Assuming that $b_{i}\left(x_{0}, x_{i}, z_{i}, U_{i}\right)$ is absolutely continuous in $U_{i}$, $\partial b_{i}\left(x_{0}, x_{i}, z_{i}, a\right) / \partial a$ exists almost everywhere and $b_{i}\left(x_{0}, x_{i}, z_{i}, U_{i}^{t}\right)$ can be written as $b_{i}\left(x_{0}, x_{i}, z_{i}, U_{i}^{t}\right)=\int_{u_{i}\left(x_{0}, x_{i}, z_{i}\right)}^{U_{t}^{t}} \frac{\partial b_{i}}{\partial a}\left(x_{0}, x_{i}, z_{i}, a\right) \mathrm{d} a$. Applying the envelop theorem to (5) yields $\frac{\partial e_{i}}{\partial U_{i}}\left(p, x_{0}, z_{i}, U_{i}\right)=-\frac{\partial b_{i}}{\partial U_{i}}\left(x_{0}, x_{i}, z_{i}, U_{i}\right)$ evaluated at $x_{i}^{c}$.

This implies that $b_{i}\left(x_{0}, x_{i}^{c}, z_{i}, U_{i}^{t}\right)=-\int_{u_{i}\left(x_{0}, x_{i}^{c}, z_{i}\right)}^{U_{i}^{t}} \frac{\partial e_{i}}{\partial a}\left(p, x_{0}, z_{i}, a\right) \mathrm{d} a$. $=e_{i}\left(p, x_{0}, z_{i}, u_{i}\left(x_{0}, x_{i}^{c}, z_{i}\right)\right)-e_{i}\left(p, x_{0}, z_{i}, U_{i}^{t}\right)$ 